\title{
Expanding Horizons for Abdominal Aortic Aneurysms
}

\author{
Rachel C. Rolph, MBBS, MA (Oxon), MRCS ${ }^{1 *}$, Matthew Waltham, MBBS, MA, PhD, FRCS ${ }^{1}$, \\ Alberto Smith, BSc, PhD ${ }^{1}$, Helena Kuivaniemi, MD, PhD, FAHA ${ }^{2,3}$ \\ ${ }^{1}$ King's College London, BHF Centre of Research Excellence \& NIHR Biomedical Research Centre at King's Health Partners, Academic \\ Department of Surgery, Cardiovascular Division and Division of Imaging Sciences, St Thomas' Hospital, London, UK \\ ${ }^{2}$ The Sigfried and Janet Weis Center for Research, Geisinger Health System, Danville, Pennsylvania, USA \\ ${ }^{3}$ Department of Surgery, Temple University School of Medicine, Philadelphia, Pennsylvania, USA
}

\begin{abstract}
Recent technological advances have allowed researchers to interrogate the genetic basis of abdominal aortic aneurysms in great detail. The results from these studies are expected to transform our understanding of this complex disease with both multiple genetic and environmental risk factors. Clinicians need to keep abreast of these genetic findings and understand the implications for their practice. Patients will become increasingly informed on genetic risk, and a new era of individualized risk assessment for AAA is just beginning. This brief update aims to provide the clinician with a succinct précis of the recent progress in this area.

Copyright (c) 2015 Science International Corp.
\end{abstract}

\section{Key Words}

Genetic • Association Studies • Risk score • Aneurysm • DNA Sequencing

\section{Introduction}

Abdominal aortic aneurysms (AAAs) are a common condition that affects approximately $4-8 \%$ of individuals greater than 65 years of age [1]. AAAs are a multifactorial disease, and we know that there is a significant genetic contribution to their formation [2]. Since the 1970s, clinicians have observed that an important risk factor for AAA formation is a positive family history for the disease with an estimated increased indi-

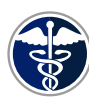

Fax +1 2037853552

E-Mail:aorta@scienceinternational.org

http://aorta.scienceinternational.org

\author{
(c) 2015 AORTA \\ Published by Science International Corp. \\ ISSN 2325-4637 \\ Accessible online at: \\ http://aorta.scienceinternational.org
}

vidual risk between two and eleven fold [3-7]. Several studies have described familial aggregation of AAA [7-10], the largest one of these studies with 233 multiplex families [11]. The AAA families displayed multiple forms of inheritance patterns suggesting that AAA is a complex, multifactorial disease.

Based on a recent twin study in Sweden, the estimated genetic contribution to overall susceptibility for AAA formation is approximately $70 \%$ [6]. In this study, 265 twins with AAA, including seven monozygotic and five concordant pairs with the disease, were identified in a Swedish population and disease registries. The odds ratio (OR) of the disease in monozygotic twins was 71 [95\% confidence interval $(\mathrm{Cl})$ : 27-183] and for dizygotic twins 7.6 (95\% Cl: 3.0-19).

\section{Genetic Studies: Have We Made Any Progress?}

The evidence supporting a strong genetic component to AAA formation has encouraged a number of research groups to perform hypothesis-driven candidate gene association studies for AAA; some of these studies have yielded highly significant findings, which we summarize in Table 1. With unbiased genome-wide association studies (GWAS), researchers have been able to interrogate the entire genomes of AAA patients, resulting in the dis-

* Corresponding Author:

Rachel C. Rolph

Academic Department of Surgery

King's College London

1 st Floor North Wing, St Thomas' Hospital, London, SE1 7EH, UK

Tel. +44(0)20 7188 0213, Fax: +44 (0)20 7928 8742, E-Mail: r.rolph1@nhs.net 
Table 1. Summary of Genetic Variants Significantly Associated with AAA Risk from Candidate Gene Association Studies.

\begin{tabular}{|c|c|c|c|c|c|}
\hline $\begin{array}{l}\text { Study with Litera- } \\
\text { ture Citation }\end{array}$ & Type of Study & $\begin{array}{l}\text { Gene } \\
\text { and Variant(s) }\end{array}$ & Potential Functional Role & $\begin{array}{l}\text { Odds Ratio } \\
\text { [95\% Confi- } \\
\text { dence Interval] }\end{array}$ & P-value \\
\hline $\begin{array}{l}\text { Morris et al. } 2014 \\
\text { [35] }\end{array}$ & Meta-analysis & MMP3: rs3025058 (5A/6A) & $\begin{array}{l}\text { Altered remodeling of extracel- } \\
\text { lular matrix }\end{array}$ & $1.48[1.23-1.78]$ & $4.0 \times 10^{-5}$ \\
\hline $\begin{array}{l}\text { Galora et al. } 2013 \\
\text { [36] }\end{array}$ & Association study & $\begin{array}{l}\text { LRP5: rs3781590* } \\
\text { and rs4988300* }\end{array}$ & Lipoprotein metabolism & $2.16[1.41-3.29]$ & $<0.0001$ \\
\hline $\begin{array}{l}\text { Jones et al., } 2013 \\
\text { [37] }\end{array}$ & Association study & SORT1: rs599839 & Lipid metabolism & $0.81[0.76-0.85]$ & $7.2 \times 10^{-14}$ \\
\hline $\begin{array}{l}\text { Helgadottir et al., } \\
2012 \text { [38] }\end{array}$ & Association study & $\begin{array}{l}\text { LPA: rs10455872a } \\
\text { and rs3798220a }\end{array}$ & $\begin{array}{l}\text { Increased atherosclerotic } \\
\text { burden }\end{array}$ & $1.23[1.11-1.36]$ & $6.0 \times 10^{-5}$ \\
\hline $\begin{array}{l}\text { Harrison et al., } 2012 \\
\text { [39] }\end{array}$ & Meta-analysis & $\begin{array}{l}\text { IL6R: rs7529229 (Asp358A- } \\
\text { la) }\end{array}$ & $\begin{array}{l}\text { Reduction in downstream } \\
\text { targets in response to IL6 } \\
\text { signaling }\end{array}$ & $0.85[0.80-0.89]$ & $2.7 \times 10^{-11}$ \\
\hline $\begin{array}{l}\text { Saracini et al., } 2012 \\
{[40]}\end{array}$ & Meta-analysis & $\begin{array}{l}\text { MMP13: rs2252070 } \\
(-77 A / G)\end{array}$ & $\begin{array}{l}\text { Altered remodeling of extracel- } \\
\text { lular matrix }\end{array}$ & $1.37[1.04-1.82]$ & \\
\hline \multirow[t]{2}{*}{ Biros et al., 2011 [41] } & Meta-analysis & TGFBR2: rs764522 & $\begin{array}{l}\text { Altered regulation of vascular } \\
\text { remodeling }\end{array}$ & $1.69[1.28-2.25]$ & $2.7 \times 10^{-4}$ \\
\hline & & TGFBR2: rs1036095 & & $1.59[1.23-2.07]$ & $4.8 \times 10^{-4}$ \\
\hline \multirow{3}{*}{$\begin{array}{l}\text { McColgan et al., } \\
2009[42]\end{array}$} & Meta-analysis & IL10: rs1800896 (nt -1082) & Interleukin signaling & $1.51[1.13-2.02]$ & 0.006 \\
\hline & & ACE: rs4646994 (I/D) & $50 \%$ increased ACE activity & $1.35[1.17-1.56]$ & $<0.0001$ \\
\hline & & MTHFR: rs8003379 (C677T) & $\begin{array}{l}70 \% \text { reduction in activity; } \\
\text { increased homocysteine levels }\end{array}$ & $1.34[1.08-1.65]$ & 0.007 \\
\hline Jones et al. 2008 [43] & Association study & AGTR1: rs5186 & Renin-angiotensin system & $1.60[1.32-1.93]$ & $1.1 \times 10^{-6}$ \\
\hline \multirow[t]{2}{*}{ Giusti et al. 2008 [44] } & Association study & MTHFD1: rs8003379 & Methionine metabolism & $0.41[0.26-0.65]$ & $<0.0001$ \\
\hline & & MTRR: rs326118 & & $0.47[0.29-0.77]$ & 0.003 \\
\hline
\end{tabular}

Studies are listed in chronological order with the most recent one first. Only studies with a minimum of 400 AAA cases and 400 controls and highly significant $(p<0.01)$ results were included. Gene symbols: ACE, angiotensin converting enzyme; AGTR1, angiotensin II type 1 receptor; IL10, interleukin 10; IL6R, interleukin 6 receptor; LRP5, low density lipoprotein receptor-related protein 5; LPA, apolipoprotein a; MMP3, matrix metalloproteinase 3; MMP13, matrix metalloproteinase 13; MTHFD1, methylenetetrahydrofolatedehydrogenase (NADP+ dependent) 1; MTHFR, 5,10-methyltetrahydrofolate reductase; MTRR, 5-methyltetrahydrofolate-homocysteine methyltransferase reductase; SORT1, sortilin 1; TGFBR1, transforming growth factor beta receptor 1; and TGFBR2, transforming growth factor beta receptor 2.

"Analyses were performed by combining the risk alleles of both variants in the same gene.

covery of four reproducible chromosomal regions that confer susceptibility to AAA formation:

i. The G-allele of a single nucleotide polymorphism (SNP), rs10757278, located on chromosome 9 p21.3 in the noncoding RNA CDKN2B-AS was first discovered in an analysis of patients with coronary artery disease (CAD) [12] and then found to be associated with multiple vascular phenotypes including AAA with an OR of 1.31 (95\% Cl: 1.22-1.41) and a highly significant $\mathrm{p}=$ $1.2 \times 10^{-12}[13,14]$. The potential role of this SNP in AAA formation is discussed below. ii. The A-allele of SNP rs7025486 located near a gene called DAB2-interacting protein (DAB2IP) on chromosome 9q33.2 was associated with AAA with an OR of 1.21 (95\% Cl: 1.14-1.28) and a highly significant $p=4.6 \times 10^{-10}[15]$. DAB2IP encodes a potent inhibitor of cell growth and survival, which results in increased smooth muscle cell susceptibility to apoptosis via the ras GTPase [16].

iii. The C-allele of SNP rs1466535 located on chromosome 12q13.3 within intron 1 of the gene for low-density-lipoprotein receptor-related protein 1 (LRP1) had a significant association with AAA 
with an OR of 1.15 (95\% Cl: 1.10-1.21) and a highly significant $p=4.52 \times 10^{-10}$ [17]. The LRP1 protein is involved in the regulation of extracellular matrix remodeling as well as vascular smooth muscle cell migration and proliferation, all of which are plausible mechanisms in AAA pathogenesis [18].

iv. The A-allele of SNP rs6511720 located on chromosome 19p13.2 in the gene for low-density-lipoprotein receptor (LDLR) had a significant association with AAA with an OR of $0.76(95 \% \mathrm{Cl}$ : $0.70-0.83$ ) and a highly significant $p=2.08 \times$ $10^{-10}$ [19]. This same variant has also been associated with lipid levels and CAD [19]. In each of these three traits, it is the A-allele that is associated with a protective effect $(O R<1)$ [19]. These findings suggest that $A A A$ and $C A D$ have at least some shared biological pathways that contribute to disease initiation or progression.

These studies have begun to unravel the genetic variants contributing to the heritability of AAA. Little, however, is known about the biological mechanisms and how they may contribute to the complex disease process. AAA is a difficult phenotype to study due to a number of aspects. It is a late-age-at-onset disease that is often fatal, which can hinder extended family analysis. Similarly, "unaffected" family members may not have manifested the disease at the time of the study but may develop AAA in due course. Overall, GWAS studies have identified loci that collectively account for a very small fraction of the observed heritability of AAA. This raises the questions: Where are the missing genetic variants contributing to AAA heritability, how to find them, and what do these variants do?

\section{Emerging Fields in Genetic Research}

With the advent of increasing technological advances in the field of DNA sequencing, the capacity for in-depth sequencing within laboratories has risen exponentially, called Next Generation Sequencing (NGS). A task that used to take months to perform is now possible in a matter of days at a vastly reduced cost, which will drive the search for AAA genes into new and exciting frontiers. Considerable success has been made using these techniques to discover novel DNA variants that underpin the heritability of rare clinical phenotypes, such as Miller syndrome [20]. The next challenge for geneticists is to begin to sequence the whole exomes and genomes of AAA patients for missing variants predisposing to AAA formation.

Using exome sequencing, a novel frame-shift mutation in the SMAD3 gene was identified in a family with autosomal dominant inheritance of thoracic aortic aneurysms with intracranial aneurysms and AAA [21]. This study illustrated the effectiveness of NGS in discovering variants if extended families are available for analysis. Researchers are, however, faced with a number of challenges when applying NGS analysis to AAA to identify causal mutations. Currently, exome coverage is not $100 \%$, some exons are poorly sequenced, and methods for calling small insertion/deletions (so called INDELs) and copy number variants (CNVs) are in further development [22]. Additional challenges related to NGS are low reproducibility of detection of variants and uncertainty about which variants are truly clinically important [23]. Another difficulty for AAA is that, when sequencing families, the segregation of the phenotype in the family may be due to nongenetic, lifestyle factors rather than a genetic sequence variant.

\section{Beyond the SNPs: Where Do We Go from Here?}

Identifying the risk conferring DNA variants is the first step in a long process to understanding the underlying disease mechanism; the next step is the challenging task of deciphering how the variant is predisposing to disease. For example, GWAS established that the sequence variant rs10757278-G on 9p21.3 confers an increased risk for CAD and AAAs [13]. The loss of the INK4a/ARF/INK4b region on chromosome 9p21 was first identified in 2006 as a key process in the cytogenetic events resulting in tumorigenesis, with further characterization since then [24, 25]. Mouse models were used to discover the mechanism by which sequence polymorphisms on chromosome 9p21 confer an increased risk of arterial disease. In culture, aortic smooth muscle cells obtained from mice with a 70-kb deletion encompassing rs 10757278 showed excessive proliferation and altered regula- 
tion of the neighboring genes [26]. CDKN2B, a tumor suppressor gene, lies within the risk locus on 9p21. An elegant study by Leeper et al. [27] demonstrated an increased aortic diameter in Cdkn2b knockout mice using the elastase AAA model. Furthermore, in vitro studies using cultured human cells showed marked apoptosis of smooth muscle cells related to increased p53 signaling pathways. Pharmacological inhibition of p53 signaling in the Cdkn2b knockout mice reversed the vascular phenotype in the elastase model. The authors concluded that reduced CDKN2B expression and increased smooth muscle cell apoptosis may underlie the 9p21.3 association with AAA. In depth sequencing of the 9p21.3 region within the Framingham cohort identified additional sequence variants [28]. Harismendy et al. [29] interrogated the 9 p21 risk alleles (rs10811656 and rs 10757278) further and demonstrated their location within enhancer intervals that interact physically with an interval downstream of IFNA21 (interferon, alpha 21). Their work established a connection between the 9p21 risk variants and aberrant vascular cell responses to inflammatory signaling, leading to CAD susceptibility. These promising advances demonstrate that we are only starting to embark on a new era in understanding aneurysm formation directed by genetic discoveries.

\section{Moving Towards an Era of Individualized Risk Assessment: The Future of AAA Diagnoses}

Until recently, classical risk factors for AAA have been used to identify patients in the general population for aneurysm screening. These risk factors have formed the basis of the national AAA screening program in the UK: for example, age over 65 years, male sex, and positive family history for the disease (http:// aaa.screening.nhs.uk/). Large-scale epidemiological studies have enabled more complex scoring algorithms for AAA risk to be constructed. Greco et al. [30] evaluated 3.1 million individuals screened for AAA and recorded their demographics and environmental risk factors. Using multivariable logistic regression analysis, they developed a novel scoring system for AAA risk that included several clinical variables and achieved a predictive accuracy $C$ statistic of 0.82 . The benefits of a healthy lifestyle including exercise, maintaining normal weight, and dietary habits were reinforced in this study, which showed that these factors do contribute to lowering risk and were included in the algorithm [30,31].

As we continue to identify additional genetic variants associated with AAA, individual genetic profiling in addition to environmental risk assessment will become possible. Recent studies on other complex diseases have shown that screening the population for only a single genetic variant for each disease has a poor predictive value; however, a profile of 50 variants, each with odds ratios of 1.02-1.15, may improve the accuracy of disease prediction [32]. Using simulated genetic models, some studies have concluded that substantial predictive power is only achieved when a large number of genetic variants ( $\mathrm{n}$ $=100-160$ ) with greater effect sizes is employed [33, 34].

The future challenge is to use the variants identified in genetic studies to produce integrated genetic and environmental predictive models to more accurately identify at risk individuals in the population that, in turn, will allow alignment of individuals to different types and intensities of screening.

\section{Conclusions}

The field of AAA genetics is rapidly progressing with new high-throughput genotyping and DNA sequencing technologies, identifying increasing numbers of genetic variants associated with the disease. With an emerging number of international collaborative projects generating GWAS data, meta-analysis of GWAS data will be required. Once a larger number of variants are identified, the possibility of integrated genetic and environmental predictive models may become a reality for personalized risk assessment and screening.

\section{Acknowledgments}

R. Rolph would like to acknowledge the National Institute for Health Research, United Kingdom for their support. 


\section{Conflict of Interest}

The authors have no conflict of interest relevant to this publication.

\section{Comment on this Article or Ask a Question}

\section{References}

1. Sakalihasan $N$, Limet $R$, Defawe OD. Abdominal aortic aneurysm. Lancet. 2005;365:1577-1589. DOI: 10.1016/S01406736(05)66459-8

2. Kuivaniemi H, Tromp G, Carey DJ, Elmore $J R$. The molecular biology and genetics of aneurysms. In: Homeister JW and Willis MS. Molecular and Translational Vascular Medicine. New York: Springer Science+Business Media; 2012, p. 3-33. DOI: 10.1007/978-161779-906-8_1

3. Clifton MA. Familial abdominal aortic aneurysms. Br J Surg. 1977;64:765-766. DOI: 10.1002/bjs.1800641102

4. Johansen K, Koepsell T. Familial tendency for abdominal aortic aneurysms. JAMA. 1986; 256:1934-1936. DOI: 10.1001/ jama.1986.03380140104031

5. Larsson E, Granath F, Swedenborg J, Hultgren R. A population-based case-control study of the familial risk of abdominal aortic aneurysm. J Vasc Surg. 2009;49:47-50. DOI: $10.1016 /$ j.jvs.2008.08.012

6. Wahlgren $\mathrm{CM}$, Larsson E, Magnusson PK, Hultgren R, Swedenborg J. Genetic and environmental contributions to abdominal aortic aneurysm development in a twin population. J Vasc Surg. 2010;51:3-7. DOI: 10.1016/j.jvs.2009.08.036

7. Tilson MD, Seashore MR. Human genetics of the abdominal aortic aneurysm. Surg Gynecol Obstet. 1984;158:129-132. PMID: 6695305

8. Golledge J, Kuivaniemi H. Genetics of abdominal aortic aneurysm. Curr Opin Cardiol. 2013;28:290-296. DOI: 10.1097/ HCO.0b013e32835f0d55

9. Kuivaniemi $\mathrm{H}$, Ryer EJ, Yoon YR, Elmore $J R$. Genetic risk factors for abdominal aortic aneurysms. In: Fischhof D and Hatig F. Aortic aneurysms: risk factors, diagnosis, surgery \& repair. Hauppauge, NY: Nova Science Publishers, Inc., 2013, p. 1-30. ISBN: 978-1-62618-459-6

10. Sakalihasan N, Defraigne J, Kerstenne $M$, Cheramy-Bien J, Smelser DT, Tromp G, et al. Family members of patients with abdominal aortic aneurysms are at increased risk for aneurysms: Analysis of 618 probands and their families from the Liege AAA Family Study. Ann Vasc Surg. 2014;28:787-797. DOI: 10.1016/j.avsg.2013.11.005

11. Kuivaniemi $H$, Shibamura $H$, Arthur $C$, Berguer R, Cole CW, Juvonen T, et al. Familial abdominal aortic aneurysms: collection of 233 multiplex families. J Vasc Surg. 2003;37:340-345. DOI: 10.1067/ mva.2003.71

12. Helgadottir A, Thorleifsson G, Manolescu A, Gretarsdottir S, Blondal T, Jonasdottir A et al. A common variant on chromosome 9 p21 affects the risk of myocardial infarction. Science. 2007;316:1491-1493. DOI: 10.1126/science. 1142842

13. Helgadottir A, Thorleifsson G, Magnusson KP, Grétarsdottir S, Steinthorsdottir V, Manolescu $A$, et al. The same sequence variant on 9 p21 associates with myocardial infarction, abdominal aortic aneurysm and intracranial aneurysm. Nat Genet. 2008;40:217224. DOI: $10.1038 / \mathrm{ng} .72$

14. Thompson AR, Cooper JA, Jones GT, Drenos $F$, van Bockxmeer FM, Biros E, Biros $E$, et al. Assessment of the association between genetic polymorphisms in transforming growth factor beta, and its binding protein (LTBP), and the presence, and expansion, of abdominal aortic aneurysm. Atherosclerosis. 2010;209:367-373. DOI: 10.1016/j.atherosclerosis.2009.09.073

15. Gretarsdottir S, Baas AF, Thorleifsson G, Holm H, den Heijer M, de Vries JP et al. Genome-wide association study identifies a sequence variant within the DAB2IP gene conferring susceptibility to abdominal aortic aneurysm. Nat Genet. DOI: 2010;42:692697. 10.1038/ng.622

16. Xie D, Gorea C, Zhoua J, Ponga R, Zhangc $\mathrm{H}, \mathrm{Yu} \mathrm{L}$, et al. DAB2IP coordinates both PI3K-Akt and ASK1 pathways for cell survival and apoptosis. Proc Natl Acad Sci U S A. 2009;106:19878-19883. DOI: 10.1073/ pnas.0908458106

17. Bown MJ, Jones GT, Harrison SC, Wright BJ, Bumpstead S, Baas AF, et al. Abdominal aortic aneurysm is associated with a variant in low-density lipoprotein receptor-related protein 1. Am J Hum Genet. 2011;89:619-

\section{DOI: 10.1016/j.ajhg.2011.10.002}

18. Wild JB, Stather PW, Sylvius N, Choke E, Sayers RD, Bown MJ. Low density lipoprotein receptor related protein 1 and abdominal aortic aneurysms. Eur J Vasc Endovasc Surg. 2012;44:127-132. DOI: 10.1016/j. ejvs.2012.05.009

19. Bradley DT, Hughes AE, Badger SA, Jones GT, Harrison SC, Wright BJ, et al. A variant in Idlr is associated with abdominal aortic aneurysm. Circ Cardiovasc Genet. 2013;6:498-504. DOI: 10.1161/CIRCGENETICS.113.000165

20. Ng SB, Buckingham KJ, Lee C, Bigham AW, Tabor HK, Dent KM, et al. Exome sequencing identifies the cause of a mendelian disorder. Nat Genet. 2010;42:30-35. DOI: 10.1038/ng.499

21. Regalado ES, Guo D, Villamizar C, Avidan $N$, Gilchrist $D$, McGillivray $B$, et al. Exome sequencing identifies SMAD3 mutations as a cause of familial thoracic aortic aneurysm and dissection with intracranial and other arterial aneurysms. Circ Res. 2011;109:680-686. DOI: 10.1161/CIRCRESAHA.111.248161

22. Do R, Kathiresan S, Abecasis GR. Exome sequencing and complex disease: practical aspects of rare variant association studies. Hum Mol Genet. 2012;21:R1-9. DOI: $10.1093 / \mathrm{hmg} / \mathrm{dds} 387$

23. Dewey FE, Grove ME, Pan C, Goldstein BA, Bernstein JA, Chaib H, et al. Clinical interpretation and implications of whole-genome sequencing. JAMA. 2014;311:10351045. DOI: $10.1001 /$ jama.2014.1717

24. Kim WY, Sharpless NE. The regulation of INK4/ARF in cancer and aging. Cell. 2006;127:265-275. DOI: 10.1016/j. cell.2006.10.003

25. Kotake $Y$, Nakagawa T, Kitagawa K, Suzuki S, Liu N, Kitagawa $M$, et al. Long non-coding RNA ANRIL is required for the PRC2 recruitment to and silencing of p15(INK4B) tumor suppressor gene. Oncogene. 2011;30:1956-1962. DOI: 10.1038/ onc. 2010.568

26. Visel A, Zhu Y, May D, Afzal V, Gong E, Attanasio $C$, et al. Targeted deletion of the 
9p21 non-coding coronary artery disease risk interval in mice. Nature. 2010;464:409412. DOI: $10.1038 /$ nature 08801

27. Leeper NJ, Leeper NJ, Raiesdana A, Kojima $Y$, Kundu RK, Cheng H, Maegdefessel L, et al. Loss of CDKN2B promotes p53-dependent smooth muscle cell apoptosis and aneurysm formation. Arterioscler Thromb Vasc Biol. 2013;33:e1-e10. DOI: 10.1161/ ATVBAHA.112.300399

28. Johnson AD, Hwang S, Voorman A, Morrison A, Peloso GM, Hsu Y, et al. Resequencing and clinical associations of the $9 p 21.3$ region: a comprehensive investigation in the Framingham heart study. Circulation. 2013;127:799-810. DOI: 10.1161/CIRCULATIONAHA.112.111559

29. Harismendy O, Notani D, Song X, Rahim NG, Tanasa B, Heintzman N, et al. 9p21 DNA variants associated with coronary artery disease impair interferon-gamma signalling response. Nature. 2011;470:264268. DOI: 10.1038/nature09753

30. Greco G, Egorova NN, Gelijns AC, Moskowitz AJ, Manganaro AJ, Zwolak RM, et al. Development of a novel scoring tool for the identification of large $>/=5 \mathrm{~cm}$ abdominal aortic aneurysms. Ann Surg. 2010;252:675682. DOI: 10.1097/SLA.0b013e3181f621c8

31. Kent KC, Zwolak RM, Egorova NN, Riles TS, Manganaro A, Moskowitz AJ, et al. Analysis of risk factors for abdominal aortic aneurysm in a cohort of more than 3 million individuals. J Vasc Surg. 2010;52:539-548. DOI: 10.1016/j.jvs.2010.05.090

32. Nguyen TV, Eisman JA. Genetic profiling and individualized assessment of fracture risk. Nat Rev Endocrinol. 2013;9:153-161. DOI: 10.1038/nrendo.2013.3

33. Hawken SJ, Greenwood CM, Hudson TJ, Kustra R, McLaughlin J, Yang Q, et al. The utility and predictive value of combina- tions of low penetrance genes for screening and risk prediction of colorectal cancer. Hum Genet. 2010;128:89-101. DOI: 10.1007/s00439-010-0828-1

34. van der Net JB, Janssens AC, Sijbrands EJ, Steyerberg EW. Value of genetic profiling for the prediction of coronary heart disease. Am Heart J. 2009;158:105-110. DOI: 10.1016/j.ahj.2009.04.022

35. Morris DR, Biros E, Cronin O, Kuivaniemi $\mathrm{H}$, Golledge J. The association of genetic variants of matrix metalloproteinases with abdominal aortic aneurysm: A systematic review and meta-analysis. Heart. 2014;100:295-302. DOI: 10.1136/heartjnl-2013-304129

36. Galora S, Saracini C, Palombella AM, Pratesi G, Pulli R, Pratesi C, et al. Low-density lipoprotein receptor-related protein 5 gene polymorphisms and genetic susceptibility to abdominal aortic aneurysm. J Vasc Surg. 2013 Oct;58(4):1062-8.e1. DOI: 10.1016/j. jvs.2012.11.092

37. Jones GT, Bown MJ, Gretarsdottir S, Romaine SP, Helgadottir A, Yu G, et al. A sequence variant associated with sortilin-1 (SORT1) on 1p13.3 is independently associated with abdominal aortic aneurysm. Hum Mol Genet. 2013 Jul 15;22(14):2941-7. DOI: $10.1093 / \mathrm{hmg} / \mathrm{ddt} 141$

38. Helgadottir A, Gretarsdottir S, Thorleifsson G, Holm H, Patel RS, Gudnason T, et al. Apolipoprotein(a) genetic sequence variants associated with systemic atherosclerosis and coronary atherosclerotic burden but not with venous thromboembolism. J Am Coll Cardiol. 2012;60:722-729. DOI: 10.1016/j.jacc.2012.01.078

39. Harrison SC, Smith AJ, Jones GT, Swerdlow DI, Rampuri R, Bown MJ, et al. Interleukin-6 receptor pathways in abdominal aortic aneurysm. Eur Heart J. 2013;34:3707-3716. DOI: 10.1093/eurheartj/ehs354
40. Saracini C, Bolli P, Sticchi E, Pratesi G, Pulli $\mathrm{R}$, Sofi $\mathrm{F}$, et al. Polymorphisms of genes involved in extracellular matrix remodeling and abdominal aortic aneurysm. J Vasc Surg. 2012;55:171-179 e2. DOI: 10.1016/j. jvs.2011.07.051

41. Biros E, Norman PE, Jones GT, van Rij AM, $\mathrm{Yu} \mathrm{G}$, Moxon JV, et al. Meta-analysis of the association between single nucleotide polymorphisms in TGF-beta receptor genes and abdominal aortic aneurysm. Atherosclerosis. 2011;219:218-223. DOI: 10.1016/j.atherosclerosis.2011.07.105

42. McColgan P, Peck GE, Greenhalgh RM, Sharma P. The genetics of abdominal aortic aneurysms: a comprehensive meta-analysis involving eight candidate genes in over 16,700 patients. Int Surg. 2009;94:350-358. PMID: 20302034

43. Jones GT, Thompsom AR, Van Bockxmeer FM, Hafez H, Cooper J, Golledge J, et al. Angiotensin II type 1 receptor $1166 \mathrm{C}$ polymorphism is associated with abdominal aortic aneurysm in three independent cohorts. Arterioscler Thromb Vasc Biol. 2008;28:764-770. DOI: 10.1161/ATVBAHA.107.155564

44. Giusti B, Saracini C, Bolli P, Magi A, Sestini I, Sticchi $E$, et al. Genetic analysis of 56 polymorphisms in 17 genes involved in methionine metabolism in patients with abdominal aortic aneurysm. J Med Genet. 2008;45:721-730. DOI: 10.1136/ jmg.2008.057851

Cite this article as: Rolph $R$, Waltham $\mathrm{M}$, Smith A, Kuivaniemi H. Expanding Horizons for Abdominal Aortic Aneurysms. AORTA. 2015;3(Issue 1): 9-15. DOI: http://dx.doi.org/10.12945/j. aorta.2015.14-041

\section{EDITOR'S QUESTIONS}

\section{What do you recommend in terms of genetic testing for AAA patients we are currently seeing in the office? Should we be testing everyone clin- ically (i.e., outside of investigational protocols)? What specific tests should we order? Where do we send samples?}

We currently do not recommend genetic testing for AAA patients outside of investigational protocols. Unfortunately, current genetic variants related to abdominal aneurysm formation have a poor pre- dictive value when tested in isolation. An increased number of variants with greater effects are required to create integrative predictive models for future testing by clinicians.

If a patient wishes to investigate their genetic risk further, a number of private genetics services are available; these, however, are not in the patients' best interests due to a lack of supporting evidence for this practice and uncertainty with the interpretation of results. 
2. Are there specific genetic variants in AAA that predict a more malignant clinical behavior? If so, which?

Current research is beginning to characterize genetic subtypes of AAA. A preliminary report with a small sample size was recently published [1] that used logistic regression studies to identify genetic variants in $L R P 1$ associated with an aggressive $A A A$ phenotype. In the future, the results of these studies may enable us to categorize patients into indolent and aggressive phenotypes, and tailor monitoring and treatment to the individual.

\section{References}

1. Duellman $\mathrm{T}$, Warren $\mathrm{CL}$, Matsumura J, Yang J. Analysis of multiple genetic polymorphisms in aggressive-growing and slow-growing abdominal aortic aneurysms. J Vasc Surg. 2014;60:613-621. 10.1016/j.jvs.2014.03.274 